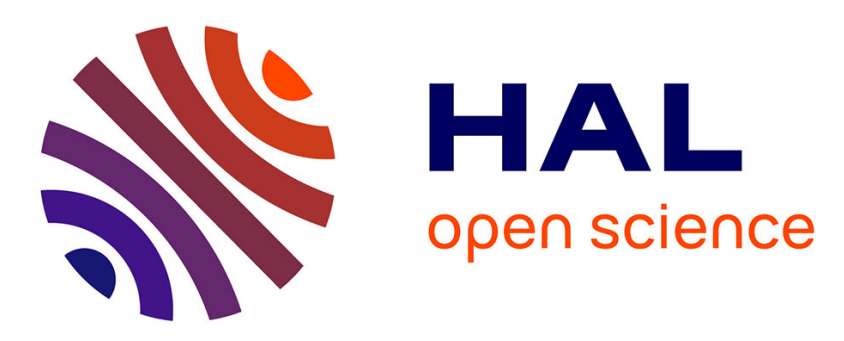

\title{
Quality of Life of Children with Congenital Heart Diseases: A Multicenter Controlled Cross-Sectional Study
}

Pascal Amedro, M Dorka, M Moniotte, M Guillaumont, A Fraisse, B. Kreitmann, B. Borm, H Bertet, C Barrea, C Ovaert, et al.

\section{To cite this version:}

Pascal Amedro, M Dorka, M Moniotte, M Guillaumont, A Fraisse, et al.. Quality of Life of Children with Congenital Heart Diseases: A Multicenter Controlled Cross-Sectional Study. Pediatric Cardiology, 2015, 36 (8), pp.1588 - 1601. 10.1007/s00246-015-1201-x . hal-01762152

\section{HAL Id: hal-01762152 \\ https://hal.umontpellier.fr/hal-01762152}

Submitted on 19 Jul 2018

HAL is a multi-disciplinary open access archive for the deposit and dissemination of scientific research documents, whether they are published or not. The documents may come from teaching and research institutions in France or abroad, or from public or private research centers.
L'archive ouverte pluridisciplinaire HAL, est destinée au dépôt et à la diffusion de documents scientifiques de niveau recherche, publiés ou non, émanant des établissements d'enseignement et de recherche français ou étrangers, des laboratoires publics ou privés. 


\title{
Quality of Life of Children with Congenital Heart Diseases: A Multicenter Controlled Cross-Sectional Study
}

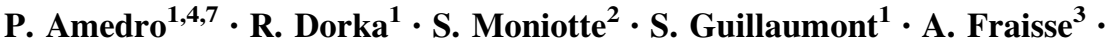 \\ B. Kreitmann ${ }^{3}$ B. Borm ${ }^{1}$ - H. Bertet ${ }^{5,6}$ - C. Barrea ${ }^{2}$ - C. Ovaert ${ }^{2,3}$. \\ T. Sluysmans ${ }^{2}$ G. De La Villeon ${ }^{1}$ M. Vincenti ${ }^{1,7} \cdot$ M. Voisin $^{1} \cdot$ P. Auquier ${ }^{4}$. \\ M. C. Picot ${ }^{5,8}$
}

\begin{abstract}
To assess the health-related quality of life (QoL) in children with congenital heart diseases (CHD) with a validated questionnaire in comparison with control children. We prospectively recruited 282 children with CHD aged from 8 to 18 years in two tertiary care centers (France and Belgium) and 180 same-age controls in randomly selected French schools. Children's QoL was self-reported with the KIDSCREEN-52 questionnaire and reported by parents with the KIDSCREEN-27. QoL scores of each dimension were compared between CHD and controls and between the classes of disease severity. Both centers were comparable for most demographic and clinical data. Age- and gender-adjusted self-reported QoL scores were lower in CHD children than in controls for physical well-being (mean \pm SEM
\end{abstract}

P. Amedro

p-amedro@chu-montpellier.fr

1 Pediatric and Congenital Cardiology Department, University Hospital, Montpellier, France

2 Pediatric and Congenital Cardiology Department, St-Luc University Hospital, Brussels, Belgium

3 Pediatric and Congenital Cardiology Department, La Timone University Hospital, Marseille, France

4 Department of Public Health, EA 3279 Research Unit, AixMarseille University, Marseille, France

5 Clinical Research and Epidemiology Unit, University Hospital, Montpellier, France

6 Clinical Investigation Center, University Hospital, Montpellier, France

7 Physiology and Experimental Biology of Heart and Muscles Laboratory - PHYMEDEXP, UMR CNRS 9214 - INSERM U1046, Montpellier University, Montpellier, France

8 Clinical Investigation Center, INSERM-CIC 1411, Montpellier, France
$45.97 \pm 0.57$ vs $50.16 \pm 0.71, p<0.0001)$, financial resources $(45.72 \pm 0.70$ vs $48.85 \pm 0.87, p=0.01)$, peers/social support $(48.01 \pm 0.72$ vs $51.02 \pm 0.88, p=$ 0.01 ), and autonomy in the multivariate analysis (47.63 \pm 0.69 vs $49.28 \pm 0.85, p=0.04)$. Parents-reported scores were lower in CHD children for physical $(p<0.0001)$, psychological well-being $(p=0.04)$, peers/social support $(p<0.0001)$, and school environment $(p<0.0001)$ dimensions. Similarly, the disease severity had an impact on physical well-being $(p<0.001)$, financial resources $(p=$ $0.05)$, and peers/social support $(p=0.01)$ for self-reported dimensions, and on physical well-being $(p<0.001)$, psychological well-being $(p<0.01)$, peers/social support $(p<0.001)$, and school environment $(p<0.001)$ for parents-reported dimensions. However, in multivariate analysis on self-reported QoL, disease severity was significantly associated with the self-perception dimension only. Self-reported QoL of CHD children was similar to that of same-age healthy children in seven of 10 dimensions, but parents-reported QoL was impaired in four of five dimensions.

Keywords Quality of life - Congenital heart disease . Children · Kidscreen · Pediatric cardiology

\section{Introduction}

Congenital heart diseases (CHD) are the first cause of congenital malformations (incidence of eight for 1000 births) [5]. Since the 1990s, great advances in prenatal diagnosis but also in pediatric cardiac surgery, intensive care, and cardiac catheterization have reduced morbidity and early mortality among CHD population, resulting in an 
increasing number of children and adolescents with CHD $[19,24]$.

In these patients, quality-of-life assessment has been given more attention recently, although patient-reported outcomes are not systematically quantified by caregivers and pediatric cardiologists, who rely primarily on clinical symptoms and disease complications [25, 30]. Yet, understanding the physical and psychosocial aspects of quality of life can enlarge the doctor-patient interaction and help on decision making in routine clinical practice [7]. Quality of life is a general and subjective concept, which has been defined as the "overall life satisfaction" [33]. In health care, a more operational definition and validated measures are needed, with good psychometric properties such as validity, reproducibility, and sensitivity to change $[8,33]$. Therefore, many clinical trials relate to "healthrelated quality of life" (QoL) where multidimensional questionnaires include at least physical, social, psychological, mental, and functional aspects [8]. In the field of congenital cardiology, questions about QoL are raised early on but will also recur at specific developmental stages. Diagnosis is now frequently made during fetal life with high detection rates in most complex CHD. Since curative or palliative treatments (surgery and/or intervention catheter) are almost always possible, parents need additional information about the future of their unborn child. The decision of a medical termination of pregnancy is no longer based on purely medical aspects and may involve concerns about QoL. In our experience and others', questions about QoL in CHD also resurface during transition from adolescence to adulthood, with a focus on sexuality and pregnancy, sports and leisure activities, and education and professional activities [45].

A systematic review on QoL studies in children and adolescents with CHD published between 2000 and 2012 reported conflicting results [6]. While some studies showed deterioration of QoL associated with the disease burden [17, 54], others described a better perception of QoL compared with healthy control subjects $[9,52]$. These results emphasize the challenge presented by the assessment of QoL in a growing child [46]. Moreover, these studies often focused on specific diseases without severity categorization. In some studies, children with severe heart failure experienced a lower QoL than those with simple CHD or controls [4, 14, 35, 50, 51, 54]. A relationship was found between CHD severity and psychological maladjustment [22]. Other studies found that QoL in children with CHD was not influenced by disease severity [10, 20, 36]. One study reported a better self-reported QoL in children with transposition of the great arteries compared with healthy norms [9]. When defining QoL as a degree of overall life satisfaction, a poor correlation was found between disease severity and QoL [32]. With the same definition, children with CHD experienced an even better QoL than controls [2, 3]. And when caregivers try to evaluate the QoL of their CHD patients, they definitely have a different perception than the child himself or his family [25].

In adult population, health-related QoL is well correlated with the level of heart failure and exercise performance among adults with $[13,15]$ or without $[23,38]$ CHD. However, these data cannot be transposed to childhood and questions remain as regards the impact of CHD on children everyday life at the time when their physical activity becomes significant, i.e., at the end of elementary school and throughout adolescence. Very few controlled studies with QoL as a primary outcome are available. They were carried out mostly among CHD adults [18] or in pediatric population but with unfamiliar QoL questionnaires $[21,48]$.

Our study aimed at assessing the QoL of CHD children aged 8-18 years in comparison with a control contemporary population using the Kidscreen, a generic validated health-related QoL questionnaire [40, 42]. Our secondary objective was to assess whether QoL was impacted by CHD severity.

\section{Methods}

\section{Study Design}

This comparative cross-sectional study was carried out between April 2009 and October 2011 (18 months) in two pediatric cardiology units (Montpellier University Hospital, France, and Brussels Saint-Luc University Hospital, Belgium) and in 10 school classes (one per level from 3rd grade (elementary school) to 12th grade (high school)) randomly selected in Southern France (Languedoc-Roussillon Region) from the Education Ministry database.

\section{Patients Population}

Children aged 8-18 years with CHD were prospectively recruited in both centers during a pediatric cardiology outpatient visit. Inclusion procedures were beforehand harmonized. Children without CHD (cardiac exploration for syncope/faint, thoracic pain, palpitations, dyspnea, etc.) were not eligible. We did not include children with any other severe chronic disease (neurodevelopmental disorder, chronic renal or respiratory failures) and children and/or families unable to understand the questionnaire. Children with recent surgical or catheter cardiac intervention (6 months delay) and hospitalized children were temporarily excluded but could be recruited during their following annual outpatient visit. 


\section{Control Population}

In the 10 selected school classes, the study was proposed to all children from 8 to 18 years and their parents. The recruitment procedure was the same for each class and common to the one at the hospital.

\section{QoL Questionnaires}

Children filled in the KIDSCREEN-52 questionnaire, the main European generic validated pediatric QoL instrument [40, 42]. The Kidscreen is a reliable, valid, sensitive, and conceptually/linguistically appropriate QoL measure in 38 countries/languages predominantly in European countries [43]. Designed for healthy and chronically ill children and adolescents aged between 8 and 18 years, it measures 10 dimensions: physical well-being (5 items), psychological well-being (6 items), moods and emotions (7 items), selfperception (5 items), autonomy (5 items), parent relations and home life (6 items), social support and peers (6 items), school environment (6 items), social acceptance (bullying) (3 items), and financial resources (3 items).

At the same time, in a separate room, parents filled in the KIDSCREEN-27 proxy questionnaire, which measures five dimensions: physical well-being (5 items), psychological well-being (7 items), autonomy and parent relations (7 items), social support and peers (4 items), and school environment (4 items) [41, 44]. QoL score is given by each dimension and varies from 0 (lowest QoL) to 100 (highest QoL).

\section{CHD Severity}

In adult population, heart failure is classically stratified upon the NYHA functional class but this classification does not apply to pediatric cardiology and is almost never used by physicians. We chose to classify our pediatric CHD population into four severity groups using previous work from Uzark et al. [54] (Table 1). ACC-CHD classification from Houyel et al. [16] was used to define the type of malformation.

\section{Formal Aspects}

This study complies with the Declaration of Helsinki. It was approved by Ethics Committees in France (South
Mediterranean IV) and Belgium (UCL Medical School) and was registered on ClinicalTrials.gov (number NCT01202916). Schools' participation was supported by the Ministry of Education Regional Authority. Informed consent was obtained from all parents.

\section{Statistical Analysis}

The study population was described with means and standard deviations (SD) or standard errors of the mean (SEM) for quantitative variables and with frequencies for qualitative variables. Quantitative variables were compared with the parametric Student's $t$ test when the distribution was Gaussian and with the Mann-Whitney test otherwise. Qualitative variables were compared with the Chi-square test or Fisher's exact test.

To assess potential selection bias, demographic and medical data were compared between patients of both centers and between included participants and subjects who refused to participate in both CHD and control groups.

To compare QoL of CHD patients and controls, we compared the age- and gender-adjusted means ( \pm Standard Error of the Mean, SEM) with an analysis of covariance (ANCOVA). For comparisons by gender between CHD and controls, scores were adjusted on age, and, for comparisons by age, scores were adjusted on gender. The same method was used to study the effect of CHD severity (four CHD severity classes and controls) on QoL. For all comparisons within subgroups and for pairwise comparisons of severity classes, the correction for multiple tests was taken into account.

To complete the study of the effect of CHD (patients vs control) or severity (four CHD severity classes) on QoL, linear multivariate regressions were performed for each score. Except for age and sex which were forced in the models, only variables with a $p$ value $\leq 0.2$ in the univariate analysis were introduced in the multivariate models. The other explicative factors were school performance (i.e., grade repetition) and medical treatment (taken into account only for analyzing the effect of severity). The final model was determined using a backward selection with a removal level of 0.15 . Colinearity between factors was tested with variance inflation factors. To test the validity of the model, the normality of residues was tested with Shapiro-Wilk test.

Table 1 CHD severity classification [54]

\begin{tabular}{ll}
\hline Severity class 1 & Mild CHD requiring no therapy or effectively treated non-operatively (catheter therapy) \\
Severity class 2 & Moderate CHD requiring no therapy or surgically corrected (curative) \\
Severity class 3 & Surgically treated CHD with significant residua or need for additional surgery \\
Severity class 4 & Complex or severe CHD, uncorrectable or palliated (includes single ventricle) \\
\hline
\end{tabular}


The two-sided significance level was 0.05 . SAS version 9 (SAS Institute, Cary, NC) was used.

\section{Results}

\section{Demographic Characteristics}

The flowchart is shown in Fig. 1. A total of $282 \mathrm{CHD}$ patients and 180 controls were included. Among eligible patients with $\mathrm{CHD}$, children refusing to participate ( $n=35,11.0 \%$ ) were similar to included CHD children $(n=282)$ in terms of sex and age but had less severe CHD (class 1: $56.5 \%$ vs $26.6 \%$, respectively).

Among eligible controls, children refusing to participate ( $n=151,45.6 \%$ ) were similar to included controls $(n=180)$ in terms of sex ratio and school class but with significantly more teenagers $(64.2$ vs $45.8 \%, p=0.002)$ and grade repetition ( 26.2 vs $9.5 \%, p<0.001)$.

Belgium and French populations of children with CHD were not significantly different for all demographic and school characteristics (Table 2). Compared to controls, our CHD population included more boys, more grade repetition, and fewer children from high school. Children with specialized education were not represented in the control group.

\section{Characteristics of CHD}

Simple CHD, such as atrial (ASD) and ventricular (VSD) septal defects $(14 \%)$, were less represented than complex
CHD (Table 3). Almost two-thirds of the patients belonged to severity class 3 or class 4 . Only $20 \%$ of children had never had any treatment before inclusion (no drugs, no cardiac surgery, and no intervention catheter). Two-thirds had had at least one cardiac surgery procedure, and one-fourth were on drugs only.

The two recruiting center populations were comparable for most medical data especially distribution of severity classes. However, interventional catheterization procedures were significantly more frequent in the Belgian group ( $n=44$ [45.8\%] vs $n=29$ [15.6\%], $p<0.001)$, with a higher number of procedures per children $(p=0.004)$. History of heart surgery did not differ between centers, but the total number of surgical procedures was lower in the French center $(p<0.0001)$. Both centers were comparable for medical devices and medication except for more betablockers prescription in the French group $(n=21$ [43.8\%] vs $\mathrm{n}=4$ [13.0\%], $p=0.004)$.

\section{QoL Among CHD Children Compared to Control Population}

As significant differences in QoL were found between boys and girls and between children (8-12 years old) and teenagers (13-18 years old), all the analyses were adjusted for age and gender.

\section{Self-Reports (KIDSCREEN-52)}

After age and gender adjustment, self-reported QoL scores were significantly lower in CHD children in three out of 10
Fig. 1 Flowchart

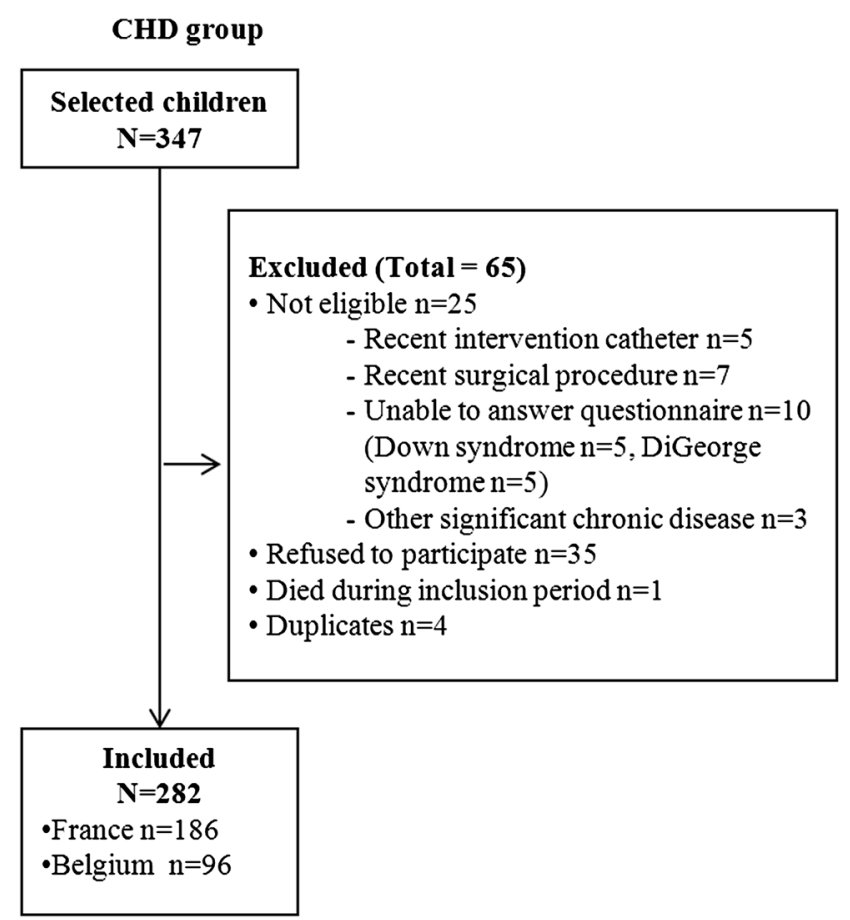


Table 2 Population characteristics

\begin{tabular}{|c|c|c|c|c|c|c|}
\hline & \multicolumn{3}{|l|}{ CHD patients } & \multirow{2}{*}{$\begin{array}{l}\text { All CHD patients } \\
N=282\end{array}$} & \multirow{2}{*}{$\begin{array}{l}\text { Controls } \\
N=180\end{array}$} & \multirow[t]{2}{*}{$p$ value } \\
\hline & $\begin{array}{l}\text { France } \\
N=186(66 \%)\end{array}$ & $\begin{array}{l}\text { Belgium } \\
N=96(34 \%)\end{array}$ & $p$ value & & & \\
\hline \multicolumn{7}{|l|}{ Sex ratio } \\
\hline Male/female & 2.1 & 1.7 & 0.38 & 1.9 & 1.1 & $<0.01$ \\
\hline \multicolumn{7}{|l|}{ Age } \\
\hline Mean (SD) & $12.2(2.9)$ & $12.6(3.2)$ & 0.34 & $12.3(3.0)$ & $12.4(2.7)$ & 0.78 \\
\hline \multicolumn{7}{|l|}{ School class } \\
\hline Elementary school & $60(33 \%)$ & $28(29 \%)$ & 0.18 & $88(32 \%)$ & $59(33 \%)$ & $<0.001$ \\
\hline Middle school & $88(49 \%)$ & $44(46 \%)$ & & $132(48 \%)$ & $73(41 \%)$ & \\
\hline High school & $24(13 \%)$ & $13(14 \%)$ & & $37(13 \%)$ & $48(27 \%)$ & \\
\hline Specialized education & $8(5 \%)$ & $11(11 \%)$ & & $19(7 \%)$ & $0(0 \%)$ & \\
\hline \multicolumn{7}{|l|}{ School level } \\
\hline Normal & $126(69 \%)$ & $63(66 \%)$ & 0.18 & $189(69 \%)$ & $157(88 \%)$ & $<0.001$ \\
\hline Advanced & $4(2 \%)$ & $0(0 \%)$ & & $4(1 \%)$ & $5(3 \%)$ & \\
\hline Repeated & $48(27 \%)$ & $32(34 \%)$ & & $80(29 \%)$ & $17(9 \%)$ & \\
\hline Dropout & $4(2 \%)$ & $0(0 \%)$ & & $4(1 \%)$ & $0(0 \%)$ & \\
\hline
\end{tabular}

dimensions: physical well-being $(p<0.0001)$, financial resources $(p=0.01)$, and peers/social support $(p=0.01)$ (Table 4).

In the multivariate analysis (Table 5), CHD significantly affected four out of 10 dimensions: physical well-being, autonomy, financial resources, and peers/social support. The performance at school (grade repetition) was associated with self-reported psychological well-being and moods and emotions.

\section{Parents Reports (KIDSCREEN-27)}

After age and gender adjustment, parents evaluation of their children's QoL with KIDSCREEN-27 was lower in the CHD group than in controls for four of five dimensions: physical well-being $(p<0.0001)$, psychological well-being $(p=0.04)$, peers/social support $(p<0.0001)$, and school environment $(p<0.0001)$ (Table 4$)$.

In multivariate analysis (Table 5), all those dimensions but psychological well-being remained significantly affected by the presence of CHD. The performance at school was associated with four out of five parents-reported dimensions.

\section{Effect of CHD Severity on QoL}

\section{Self-Reports (KIDSCREEN-52)}

Children's self-scorings were statistically different between the five severity classes (controls included) in three out of 10 dimensions: physical well-being $(p<0.001)$, financial resources $(p=0.05)$, and peers/social support $(p=0.01)$ (Fig. 2). Main differences were observed between controls and stages 2, 3, and 4; no significant differences were observed between the severity classes from 1 to 4 .

In multivariate analysis among CHD children (Table 6), the severity of CHD disease tended to impact self-perception $\left(p_{\text {global }}=0.07\right.$, not reported $)$.

\section{Parents Reports (KIDSCREEN-27)}

Parents-reported QoL scores significantly differed between the five severity classes (controls included) in four out of five dimensions: physical well-being ( $p<0.001)$, psychological well-being $(p<0.01)$, peers/social support $(p<0.001)$, and school environment $(p<0.001)$ (Fig. 3).

In multivariate analysis among CHD children (Table 6), the severity of CHD affected physical well-being ( $p_{\text {global }}$ $<0.0001$, not reported), psychological well-being $\left(p_{\text {global }}=0.03\right.$, not reported $)$, and school environment $\left(p_{\text {global }}=0.05\right.$, not reported $)$.

QoL scores for the least severe CHD (class 1) were never significantly different from controls.

\section{Discussion}

This cross-sectional observational study assessed the QoL of a large cohort of 282 young children and adolescents with CHD in comparison with a control healthy population ( $n=180$ ) using a validated questionnaire [7], which fulfills the World Health Organization recommendations on 
Table 3 CHD children: medical characteristics

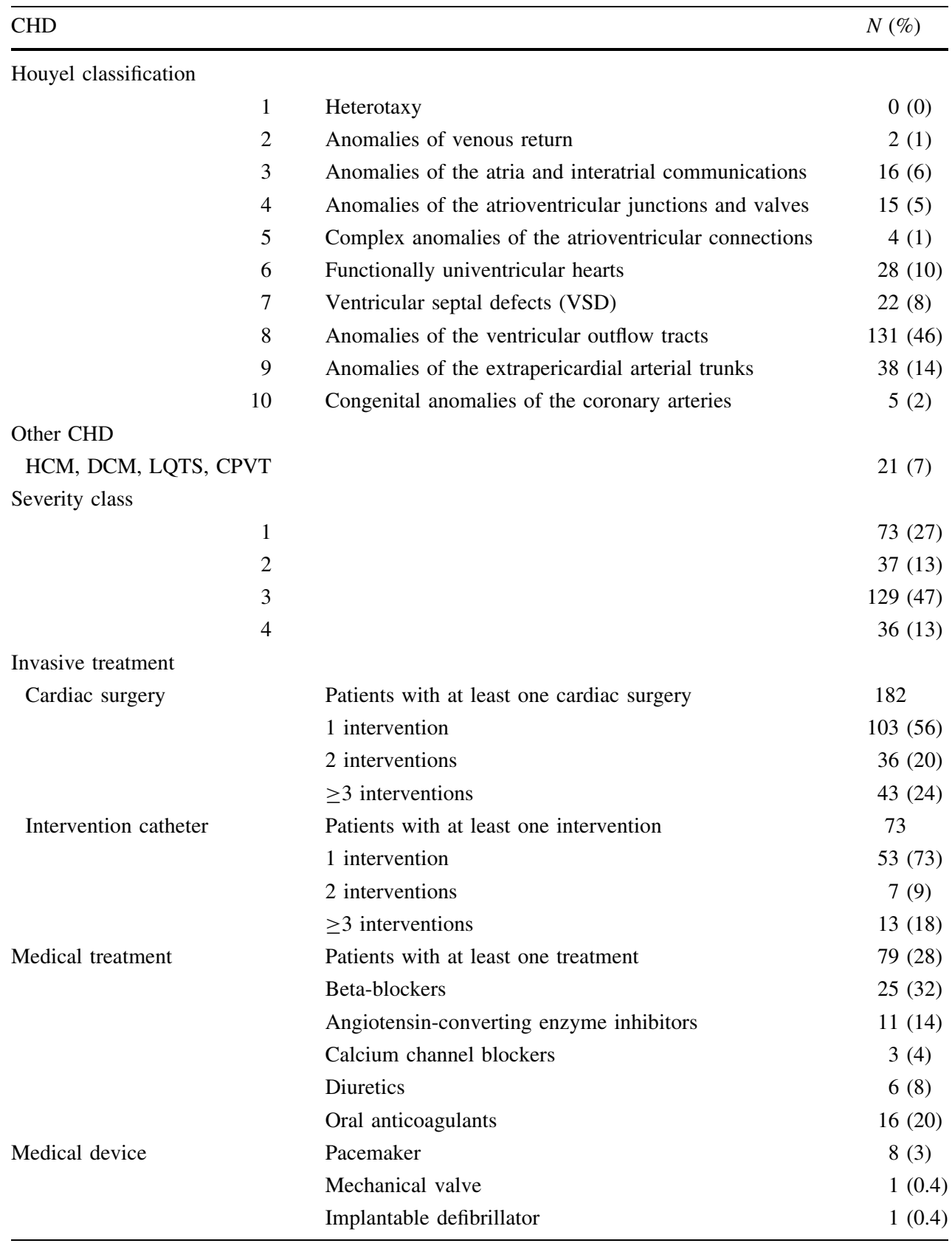

$H C M$ hypertrophic cardiomyopathy, DCM dilated cardiomyopathy, LQTS long QT syndrome, CPVT catecholaminergic polymorphic ventricular tachycardia
QoL studies by taking into consideration at least these dimensions: physical, emotional, mental, social, and all-day life functional aspects of health. This study showed that self-reported QoL of children with CHD aged from 8 to 18 years compared to same-age controls was altered in several dimensions: physical well-being (i.e., the dimension which most reflects disease impact), financial resources, peers/social support, and autonomy (only in multivariate analysis for this last one). In contrast, parents of patients assessed QoL as impaired in four out of five evaluated dimensions. Our control children selected among regular school classes might experience more autonomy and social activities than CHD children. However, most CHD children also went to school with very few dropouts. Pediatric cardiologists usually agree that CHD children are more brooded by their parents and have less autonomy. In most cases, physical activity and sports are authorized under individual pediatric cardiologist's prescription [26, 
Table 4 Kidscreen scores: comparisons between CHD and control children

\begin{tabular}{|c|c|c|c|c|c|}
\hline & \multicolumn{2}{|l|}{$\mathrm{CHD}$} & \multicolumn{2}{|l|}{ Controls } & \multirow[t]{2}{*}{$p$ value } \\
\hline & $n / N$ & Mean (SEM) & $n / N$ & Mean (SEM) & \\
\hline \multicolumn{6}{|c|}{ KIDSCREEN-52: children self-reported dimensions } \\
\hline Physical well-being & $278 / 282$ & $45.97(0.57)$ & $171 / 180$ & $50.16(0.71)$ & $<0.0001$ \\
\hline Psychological well-being & $279 / 282$ & $49.43(0.57)$ & $171 / 180$ & $49.64(0.71)$ & 0.82 \\
\hline Moods and emotions & $278 / 282$ & $53.96(0.64)$ & $171 / 180$ & $53.87(0.79)$ & 0.94 \\
\hline Self-perception & $277 / 282$ & $50.75(0.56)$ & $171 / 180$ & $50.59(0.69)$ & 0.86 \\
\hline Autonomy & $278 / 282$ & $47.63(0.69)$ & $171 / 180$ & $49.28(0.85)$ & 0.13 \\
\hline Parent relation and home life & $279 / 282$ & $48.75(0.63)$ & $171 / 180$ & $48.15(0.78)$ & 0.55 \\
\hline Financial resources & $273 / 282$ & $45.72(0.70)$ & $162 / 180$ & $48.85(0.87)$ & 0.01 \\
\hline Peers and social support & $277 / 282$ & $48.01(0.72)$ & $171 / 180$ & $51.02(0.88)$ & 0.01 \\
\hline School environment & $272 / 282$ & $50.17(0.67)$ & $170 / 180$ & $51.93(0.82)$ & 0.09 \\
\hline Bullying & $275 / 282$ & $49.87(0.58)$ & $170 / 180$ & $50.80(0.71)$ & 0.31 \\
\hline \multicolumn{6}{|c|}{ KIDSCREEN-27: parents-reported dimensions } \\
\hline Physical well-being & $274 / 282$ & $43.81(0.56)$ & $177 / 180$ & $49.89(0.68)$ & $<0.0001$ \\
\hline Psychological well-being & $275 / 282$ & $50.65(0.65)$ & $176 / 180$ & $52.73(0.79)$ & 0.04 \\
\hline Autonomy and parent relation & $276 / 282$ & $45.96(0.64)$ & $175 / 180$ & $47.35(0.78)$ & 0.17 \\
\hline Peers and social support & $277 / 282$ & $44.48(0.76)$ & $178 / 180$ & $49.72(0.91)$ & $<0.0001$ \\
\hline School environment & $276 / 282$ & $47.67(0.62)$ & $178 / 180$ & $51.56(0.75)$ & $<0.0001$ \\
\hline
\end{tabular}

Mean $( \pm$ SEM) adjusted on gender and continuous age. Significant $p$ values $<0.05$ are marked in bold
28], but parents and teachers often stigmatize CHD and some of these children might remain on the sidelines. Moola et al. mentioned parental barriers to physical activity for youngsters with CHD [29].

The impact on the self-reported "financial resources" dimension may not only be related to a lack of autonomy given by the parents. Indeed, low income in CHD families has been previously reported [47, 55], suggesting that parents are more likely to be unemployed to take care of their child. In a large cohort of children with single ventricle, McCrindle et al. showed that a lower family income had a negative impact on both physical and psychosocial QoL scores [27]. A low socioeconomic status among CHD adults has also been recently found to be associated with exercise intolerance [11] and "avoidance behavior" coping strategy [12]. Therefore, caregivers should consider this financial aspect in the follow-up of patients with CHD, even in pediatric age.

The impact on the "peers and social support" dimension found in our study, for both self-reports and parents reports, also needs to be taken into consideration. Indeed, behavioral and emotional problems have been described among CHD children $[49,53]$, whereas a good peer relationship has been identified as an important factor of identity formation in teenagers with CHD [39].

In our study, CHD patients were classified into four severity groups [54] and compared with controls. Although children's self-scorings were statistically different between the five severity classes (including controls) in three dimensions (physical well-being, financial resources, and peers/social support), limited association between self-reported QoL and the severity of the heart disease was detected in multivariate analysis. Parents were more inclined to identify the impact of disease severity on their child's QoL, and in multivariate analysis, three out of five parentsreported dimensions (physical and psychological well-being, school environment) were significantly affected by disease severity. QoL of the least severe patients was not different from controls, which suggests that children with the simplest CHD can be assimilated to the general children population with respect to their QoL.

Our results show that the physical well-being is deteriorated in CHD patients compared with the normal population, for both self- and parents-reported scores. This dimension particularly reflects the impact of the heart disease, supporting the use of the Kidscreen questionnaire as a generic health-related QoL questionnaire for CHD children. It is a valuable tool to consider when defining patient-reported outcomes (PROs) for clinical trials in pediatric cardiology.

On the other side, the absence of strong correlations between most of the "non-physical" dimensions and the presence or severity of CHD is not surprising and rather positive from the patients' point of view. Indeed, their QoL does not exclusively depend on their physical disability related to their CHD. In our population, most "non-physical" dimensions scores were close to those of normal children, even for the most severely ill patients. Despite 
Table 5 Kidscreen scores: multivariate analysis (with CHD vs control)

\begin{tabular}{|c|c|c|c|c|}
\hline & $\begin{array}{l}\text { Gender } \\
\text { Girls vs boys }\end{array}$ & Age (years) & $\begin{array}{l}\text { Group } \\
\text { CHD vs control }\end{array}$ & $\begin{array}{l}\text { Grade repetition } \\
\text { No vs Yes }\end{array}$ \\
\hline \multicolumn{5}{|c|}{ KIDSCREEN-52: children self-reported dimensions } \\
\hline Physical well-being & $\begin{array}{l}-3.5(0.9) \\
<0.001\end{array}$ & $\begin{array}{l}-0.7(0.2) \\
<0.0001\end{array}$ & $\begin{array}{l}-3.8(0.9) \\
<0.0001\end{array}$ & $\begin{array}{l}2.0(1.2) \\
0.08\end{array}$ \\
\hline Psychological well-being & $\begin{array}{l}-1.9(0.9) \\
0.04\end{array}$ & $\begin{array}{l}-0.6(0.2) \\
<0.001\end{array}$ & $\begin{array}{l}0.3(0.9) \\
0.77\end{array}$ & $\begin{array}{l}2.7(1.1) \\
0.02\end{array}$ \\
\hline Moods and emotions & $\begin{array}{l}-2.6(1.0) \\
0.01\end{array}$ & $\begin{array}{l}-0.2(0.2) \\
0.30\end{array}$ & $\begin{array}{l}0.5(1.1) \\
0.62\end{array}$ & $\begin{array}{l}2.7(1.3) \\
0.04\end{array}$ \\
\hline Self-perception & $\begin{array}{l}-3.5(0.9) \\
<0.0001\end{array}$ & $\begin{array}{l}-0.6(0.2) \\
<0.0001\end{array}$ & $\begin{array}{l}0.2(0.9) \\
0.80\end{array}$ & $-*$ \\
\hline Autonomy & $\begin{array}{l}-2.8(1.1) \\
0.01\end{array}$ & $\begin{array}{l}-0.4(0.2) \\
0.05\end{array}$ & $\begin{array}{l}-2.3(1.1) \\
0.04\end{array}$ & $\begin{array}{l}-2.2(1.4) \\
0.11\end{array}$ \\
\hline Parent relation and home life & $\begin{array}{l}-2.1(1.0) \\
0.04\end{array}$ & $\begin{array}{l}-0.3(0.2) \\
0.09\end{array}$ & $\begin{array}{l}0.8(1.0) \\
0.44\end{array}$ & $\begin{array}{l}1.9(1.3) \\
0.14\end{array}$ \\
\hline Financial resources & $\begin{array}{l}-0.8(1.1) \\
0.46\end{array}$ & $\begin{array}{l}0.6(0.2) \\
<0.01\end{array}$ & $\begin{array}{l}-3.2(1.1) \\
<0.01\end{array}$ & $-*$ \\
\hline Peers and social support & $\begin{array}{l}-0.4(1.1) \\
0.72\end{array}$ & $\begin{array}{l}-0.5(0.2) \\
0.02\end{array}$ & $\begin{array}{l}-3.1(1.1) \\
<0.01\end{array}$ & $-*$ \\
\hline School environment & $\begin{array}{l}0.1(1.0) \\
0.96\end{array}$ & $\begin{array}{l}-1.5(0.2) \\
<0.0001\end{array}$ & $\begin{array}{l}-1.7(1.0) \\
0.10\end{array}$ & $-*$ \\
\hline Bullying & $\begin{array}{l}0.7(1.0) \\
0.48\end{array}$ & $\begin{array}{l}0.5(0.2) \\
<0.001\end{array}$ & $\begin{array}{l}-0.9(0.9) \\
0.31\end{array}$ & -* \\
\hline KIDSCREEN-27: parents-repo & d dimensions & & & \\
\hline Physical well-being & $\begin{array}{l}-4.2(0.9) \\
<0.0001\end{array}$ & $\begin{array}{l}-1.1(0.2) \\
<0.0001\end{array}$ & $\begin{array}{l}-5.7(0.9) \\
<0.001\end{array}$ & $\begin{array}{l}2.2(1.1) \\
0.05\end{array}$ \\
\hline Psychological well-being & $\begin{array}{l}-1.9(1.0) \\
0.06\end{array}$ & $\begin{array}{l}-0.8(0.2) \\
<0.0001\end{array}$ & $\begin{array}{l}-1.6(1.0) \\
0.14\end{array}$ & $\begin{array}{l}3.4(1.3) \\
0.01\end{array}$ \\
\hline Autonomy and parent relation & $\begin{array}{l}-0.3(1.0) \\
0.77\end{array}$ & $\begin{array}{l}0.3(0.2) \\
0.15\end{array}$ & $\begin{array}{l}-1.0(1.0) \\
0.33\end{array}$ & $\begin{array}{l}2.8(1.3) \\
0.03\end{array}$ \\
\hline Peers and social support & $\begin{array}{l}1.4(1.2) \\
0.24\end{array}$ & $\begin{array}{l}-0.3(0.2) \\
0.13\end{array}$ & $\begin{array}{l}-5.0(1.2) \\
<0.001\end{array}$ & $\begin{array}{l}2.2(1.5) \\
0.14\end{array}$ \\
\hline School environment & $\begin{array}{l}1.0(1.0) \\
0.29\end{array}$ & $\begin{array}{l}-0.8(0.2) \\
<0.0001\end{array}$ & $\begin{array}{l}-3.0(1.0) \\
<0.01\end{array}$ & $\begin{array}{l}5.6(1.2) \\
<0.0001\end{array}$ \\
\hline
\end{tabular}

Values are linear regression coefficients $\beta$ (standard error) and $p$ values

* Not maintained in the models if $p \geq 0.15$ their illness, these patients seem to appreciate the "little things in life" after having survived surgical interventions (meaningfulness), being prepared to face challenges and stresses (manageability) and reaching a high comprehensibility of their illness [31]. The "disability paradox" emphasizes that individuals with functional impairment might experience a higher life satisfaction than their "healthy" comrades [31]. As CHD patients were born with their heart disease, they might have learned early in their life how to develop a strong "sense of coherence" and select the right coping strategies [1]. Recent studies have shown that among CHD adolescents, a high sense of coherence was particularly related to the mental components of QoL [34, 36]. Therefore, some patients with the most severe CHD manage to find their life "meaningful," as it has been described in adults with single ventricles [37]. The immediate circle of the younger patients probably helps them coping with this heart disease that they were born with: Neuner et al. [36] found that the sense of coherence of CHD patients was positively correlated with family-related and friend-related well-being. Other mechanisms specific to pediatric population (denial, family support, etc.) probably facilitate these coping strategies in CHD children [49, 53]. If we consider that QoL measurement stands as an ideal 


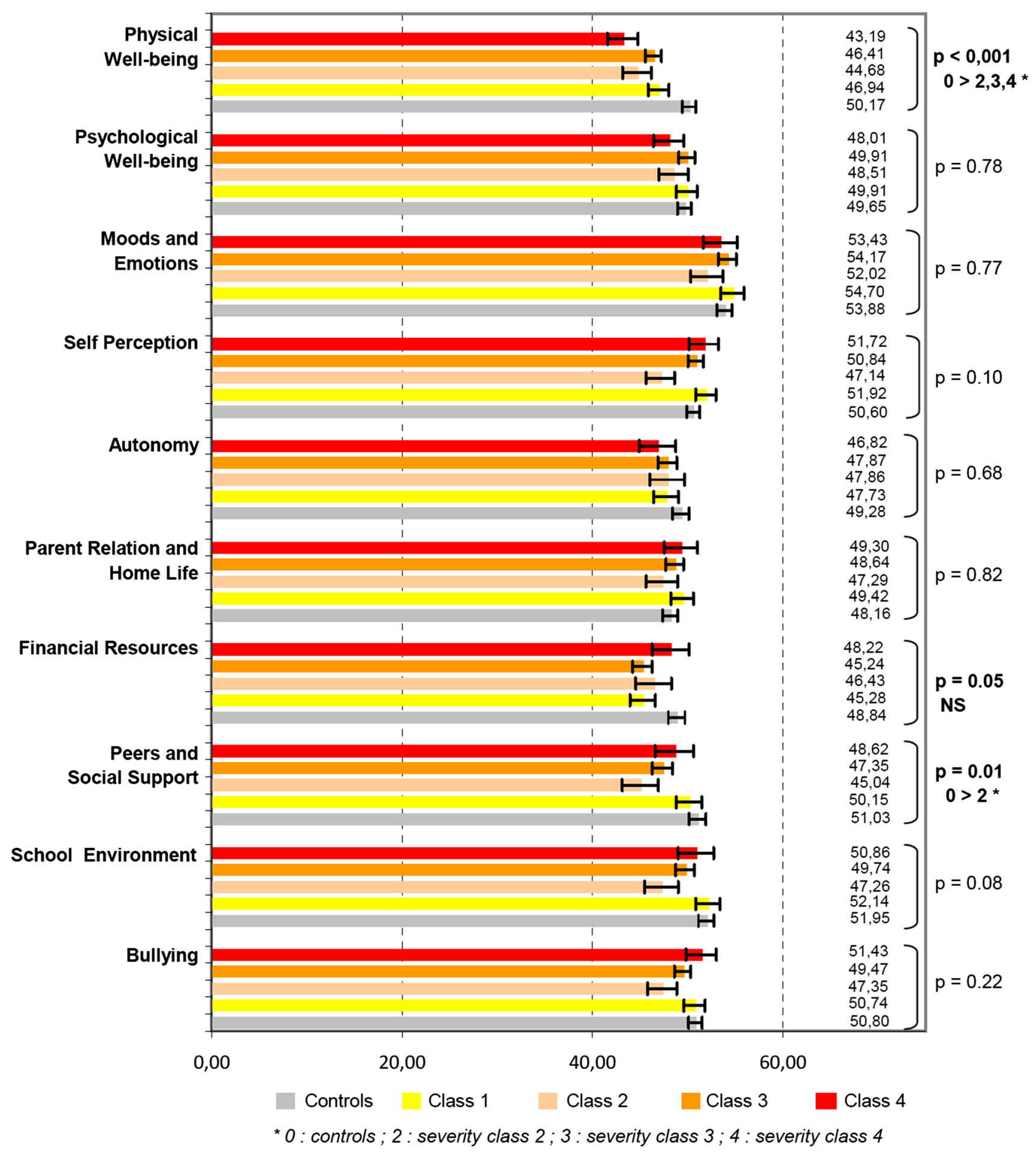

Fig. 2 Self-reported QoL scores based on severity class after adjustment for gender and continuous age (adjusted mean \pm SEM)

"PRO" in pediatric cardiology clinical trials, a response shift process among CHD children could also be discussed in the light of these results.

We also pointed out interesting differences between self- and parents-reported QoL. This aspect is well known, with parents usually reporting lower scores for their children's QoL [54]. From the parents' point of view, more dimensions were altered than from the children's, especially school environment and psychological well-being. Pediatric and congenital cardiologists should take into consideration this different vision of QoL between parents and children, especially when applying to the entire family 
Table 6 Kidscreen scores: multivariate analysis (with CHD severity classes 1/2/3/4)

\begin{tabular}{|c|c|c|c|c|c|c|c|}
\hline & \multirow{2}{*}{$\begin{array}{l}\text { Gender } \\
\text { Girls vs boys }\end{array}$} & \multirow[t]{2}{*}{ Age (years) } & \multicolumn{3}{|c|}{ CHD severity classes } & \multirow{2}{*}{$\begin{array}{l}\text { Grade repetition } \\
\text { No vs Yes }\end{array}$} & \multirow{2}{*}{$\begin{array}{l}\text { Medical treatment } \\
\text { No vs Yes }\end{array}$} \\
\hline & & & 1 vs 4 & 2 vs 4 & 3 vs 4 & & \\
\hline \multicolumn{8}{|c|}{ KIDSCREEN-52: children self-reported dimensions } \\
\hline \multirow[t]{2}{*}{ Physical well-being } & $-3.6(1.3)$ & $-0.6(0.2)$ & $4.2(2.2)$ & $2.4(2.5)$ & $3.9(2.0)$ & $2.1(1.4)$ & $-*$ \\
\hline & $<0.01$ & $<0.01$ & 0.06 & 0.33 & 0.05 & 0.13 & \\
\hline \multirow[t]{2}{*}{ Psychological well-being } & $-1.3(1.2)$ & $-0.3(0.2)$ & $1.2(2.1)$ & $-0.1(2.4)$ & $1.8(1.9)$ & $3.0(1.3)$ & $-*$ \\
\hline & 0.29 & 0.13 & 0.57 & 1.0 & 0.35 & 0.03 & \\
\hline \multirow[t]{2}{*}{ Moods and emotions } & $-0.5(1.4)$ & $0.02(0.2)$ & $-2.8(2.7)$ & $-4.7(2.9)$ & $-2.2(2.4)$ & $2.6(1.5)$ & $4.3(1.8)$ \\
\hline & 0.71 & 0.94 & 0.29 & 0.10 & 0.38 & 0.09 & 0.02 \\
\hline \multirow[t]{2}{*}{ Self-perception } & $-2.5(1.2)$ & $-0.6(0.2)$ & $-0.8(2.3)$ & $-5.3(2.5)$ & $-1.4(2.1)$ & $2.4(1.5)$ & $-*$ \\
\hline & 0.04 & $<0.01$ & 0.74 & 0.03 & 0.51 & 0.12 & \\
\hline \multirow[t]{2}{*}{ Autonomy } & $-1.9(1.4)$ & $-0.02(0.2)$ & $2.5(2.4)$ & $3.1(2.7)$ & $2.9(2.2)$ & $-3.2(1.5)$ & $-*$ \\
\hline & 0.17 & 0.94 & 0.29 & 0.25 & 0.18 & 0.03 & \\
\hline \multirow[t]{2}{*}{ Parent relation and home life } & $-2.2(1.3)$ & $-0.3(0.2)$ & $0.7(2.2)$ & $-1.0(2.5)$ & $0.3(2.1)$ & $-*$ & $-*$ \\
\hline & 0.10 & 0.25 & 0.77 & 0.68 & 0.88 & & \\
\hline \multirow[t]{2}{*}{ Financial resources } & $-1.4(1.5)$ & $0.9(0.3)$ & $-3.1(2.6)$ & $-1.8(2.9)$ & $-2.8(2.4)$ & $2.7(1.7)$ & $-*$ \\
\hline & 0.34 & $<0.01$ & 0.24 & 0.53 & 0.23 & 0.11 & \\
\hline \multirow[t]{2}{*}{ Peers and social support } & $0.6(1.6)$ & $-0.3(0.3)$ & $1.8(2.7)$ & $-3.0(3.1)$ & $-0.7(2.5)$ & $-*$ & $-*$ \\
\hline & 0.72 & 0.33 & 0.51 & 0.33 & 0.77 & & \\
\hline \multirow[t]{2}{*}{ School environment } & $1.3(1.5)$ & $-1.3(0.3)$ & $1.9(2.4)$ & $-3.1(2.8)$ & $-0.4(2.3)$ & $-*$ & $-*$ \\
\hline & 0.38 & $<0.0001$ & 0.45 & 0.26 & 0.86 & & \\
\hline \multirow[t]{2}{*}{ Bullying } & $1.3(1.2)$ & $0.4(0.2)$ & $-0.4(2.1)$ & $-4.0(2.4)$ & $-1.4(1.9)$ & $-*$ & $-*$ \\
\hline & 0.31 & 0.05 & 0.86 & 0.09 & 0.48 & & \\
\hline \multicolumn{8}{|c|}{ KIDSCREEN-27: parents-reported dimensions } \\
\hline \multirow[t]{2}{*}{ Physical well-being } & $-4.0(1.1)$ & $-0.8(0.2)$ & $9.3(1.8)$ & $8.3(2.1)$ & $6.2(1.7)$ & $-*$ & $-*$ \\
\hline & $<0.001$ & $<0.0001$ & $<0.0001$ & $<0.0001$ & $<0.001$ & & \\
\hline \multirow[t]{2}{*}{ Psychological well-being } & $-2.3(1.3)$ & $-0.5(0.2)$ & $6.0(2.3)$ & $1.4(2.5)$ & $3.6(2.1)$ & $3.4(1.5)$ & -* \\
\hline & 0.09 & 0.03 & 0.01 & 0.57 & 0.09 & 0.02 & \\
\hline \multirow[t]{2}{*}{ Autonomy and parent relation } & $0.5(1.3)$ & $0.2(0.2)$ & $2.4(2.2)$ & $2.7(2.5)$ & $2.1(2.0)$ & $-*$ & $-*$ \\
\hline & 0.73 & 0.47 & 0.26 & 0.27 & 0.28 & & \\
\hline \multirow[t]{2}{*}{ Peers and social support } & $3.1(1.5)$ & $-0.2(0.2)$ & $1.6(2.5)$ & $-0.8(2.9)$ & $0.7(2.3)$ & $-*$ & -* \\
\hline & 0.04 & 0.32 & 0.52 & 0.77 & 0.75 & & \\
\hline \multirow[t]{2}{*}{ School environment } & $1.7(1.3)$ & $-0.6(0.2)$ & $4.1(2.1)$ & $-0.6(2.4)$ & $0.7(2.0)$ & $6.3(1.4)$ & -* \\
\hline & 0.19 & 0.01 & 0.05 & 0.81 & 0.71 & $<0.0001$ & \\
\hline
\end{tabular}

Values are linear regression coefficients $\beta$ (standard error) and $p$ values

* Not maintained in the models if $p \geq 0.15$

the CHD transition program from childhood to adulthood care [45].

This gap between self- and parents-reported QoL scores is well known in chronic diseases and gives rise to a question in the field of pediatric cardiology: if we can agree that our results support the use of physical well-being scores as "PRO" in a pediatric cardiology clinical trial, which questionnaire-child or parent_-should be taken into account? We plan to answer this question in correlating our QoL results to cardiopulmonary exercise tests $\left(\mathrm{VO} 2_{\max }\right)$ performed among our CHD study population.

\section{Study Limitations}

Patients were recruited in two different countries, and controls were recruited in France. Environmental and cultural factors, surgical management, medical therapy, school systems might influence QoL evaluation. However, France and Belgium (Wallonia) are two European countries geographically and culturally related, with the same mother tongue and similar scholar systems. Both centers are tertiary care referral university departments taking care of complex CHD from fetus to adulthood, with extremely 


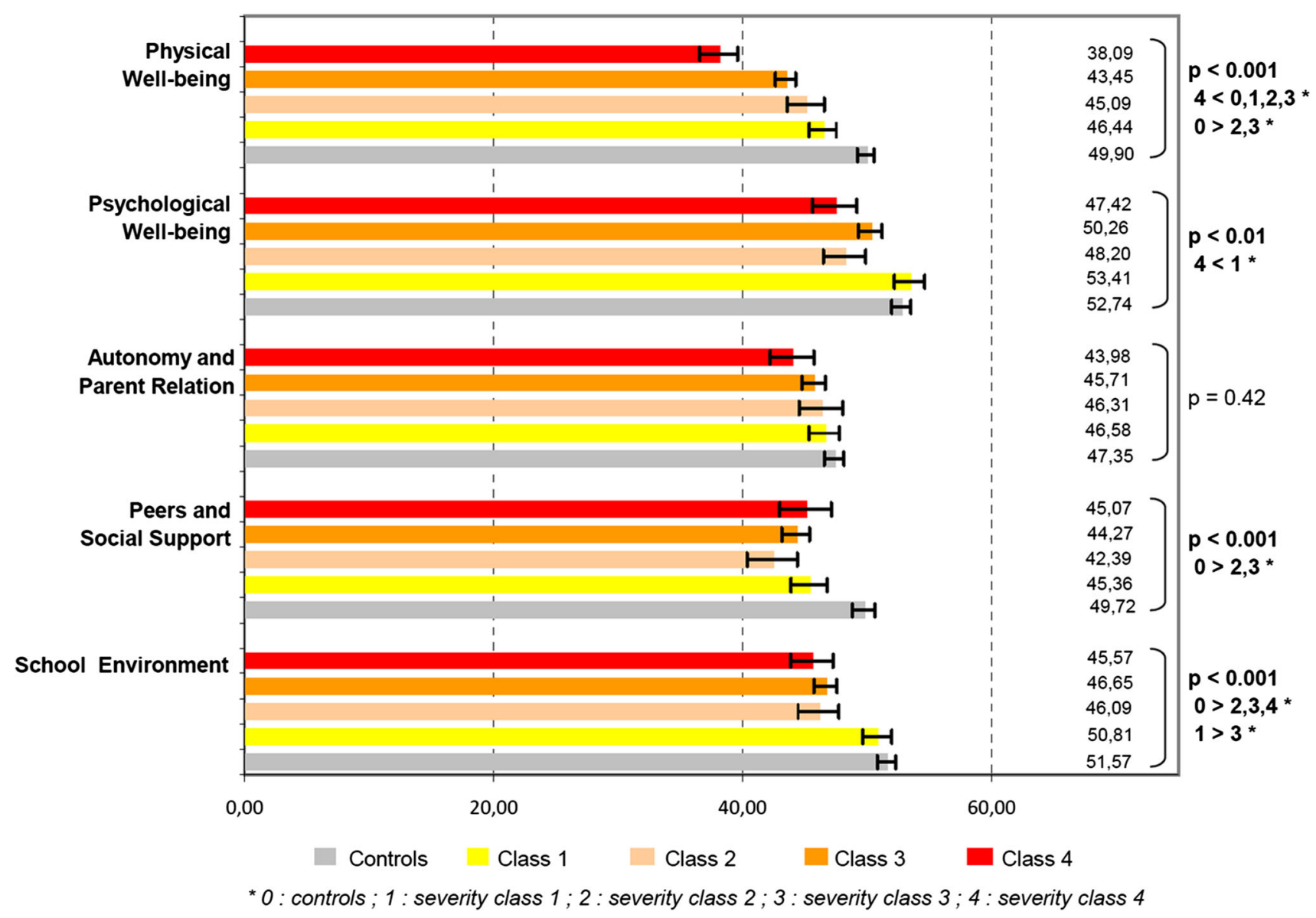

Fig. 3 Parents-reported QoL scores based on severity class after adjustment for gender and continuous age (adjusted mean \pm SEM)

similar demographic data and similar active file of patients. We purposely collected no medical data among control population to minimize the duration of study participation for parents and children and therefore increase participation rate. This bias is very limited by a low prevalence of severe chronic diseases in general pediatric population attending school, whereas congenital heart diseases are the first congenital anomalies [5].

The distribution of defects within our CHD group is different from that within the general CHD population with, for instance, $8 \%$ VSD and $46 \%$ ventricular outflow tracts anomalies (52 and $20 \%$ in the French registry, respectively) [16]. The large number of complex heart defects precludes the extension of our results to the whole population of children with CHD. However, this bias was compensated by the investigation of the effect of severity class on QoL. Children were not included during hospitalization to limit the impact on QoL evaluation of a stressful period, a complication, or a diagnosis announcement. As all of our CHD patients have an annual follow-up, these hospitalized children were recruited afterwards during the outpatient follow-up.

\section{Conclusion}

In our study, self-reported QoL scores among children with congenital heart diseases are close to those of same-age controls. Physical well-being, financial resources, social and peers support, and autonomy were significantly impaired. In multivariate analysis, we found limited association between self-reported QoL and the severity of the heart condition. QoL of the least severe patients was not significantly different from that of controls. As in many other pediatric QoL studies, parents-reported QoL of their children was not superimposed to self-reported evaluation: parents-reported QoL was impaired in four out of five dimensions, whereas self-reported QoL did not differ from that of same-age healthy children in seven out of $10 \mathrm{di}-$ mensions. Parents' scores were more associated than selfreports with the severity of their child's CHD. QoL should be taken into consideration by caregivers when planning the transition of CHD patients and families from childhood to adulthood care. When designing a clinical trial in the field of pediatric cardiology, we recommend using the Kidscreen physical well-being scores as a patient-related 
outcome. Furthermore, to discriminate the real physical impairment of the heart condition and its expression through a QoL questionnaire, we plan to correlate these QoL data with cardiopulmonary exercise capacity.

Acknowledgments We thank Christophe Azorin, National Ministry of Education, for his collaboration to perform the study in schools. We thank Anne Cadène for the quality of study monitoring. Medical writing assistance was provided by Valerie Macioce and Sylvie Ertel. This work was supported by Montpellier University Hospital (PHRC).

Conflict of interest None.

\section{References}

1. Antonovsky A (1985) The life cycle, mental health and the sense of coherence. Isr J Psychiatry Relat Sci 22(4):273-280

2. Apers S, Moons P, Goossens E, Luyckx K, Gewillig M, Bogaerts K, Budts W, Di I (2013) Sense of coherence and perceived physical health explain the better quality of life in adolescents with congenital heart disease. Eur J Cardiovasc Nurs 12(5):475-483. doi:10.1177/1474515113477955

3. Apers S, Luyckx K, Rassart J, Goossens E, Budts W, Moons P (2013) Sense of coherence is a predictor of perceived health in adolescents with congenital heart disease: a cross-lagged prospective study. Int J Nurs Stud 50(6):776-785. doi:10.1016/j. ijnurstu.2012.07.002

4. Berkes A, Varni JW, Pataki I, Kardos L, Kemeny C, Mogyorosy G (2010) Measuring health-related quality of life in Hungarian children attending a cardiology clinic with the Pediatric Quality of Life Inventory. Eur J Pediatr 169(3):333-347. doi:10.1007/ s00431-009-1059-0

5. Bernier PL, Stefanescu A, Samoukovic G, Tchervenkov CI (2010) The challenge of congenital heart disease worldwide: epidemiologic and demographic facts. Semin Thorac Cardiovasc Surg Pediatr Cardiac Surg Annu 13(1):26-34. doi:10.1053/j.pcsu. 2010.02.005

6. Bertoletti J, Marx GC, Hattge Junior SP, Pellanda LC (2014) Quality of life and congenital heart disease in childhood and adolescence. Arq Bras Cardiol 102(2):192-198

7. Bullinger M, Ravens-Sieberer U (1995) General principles, methods and areas of application of quality of life research in children. Praxis der Kinderpsychologie und Kinderpsychiatrie 44(10):391-399

8. Bullinger M, Schmidt S, Petersen C, Erhart M, Ravens-Sieberer U (2007) Methodological challenges and potentials of healthrelated quality of life evaluation in children with chronic health conditions under medical health care. Med Klin 102(9):734-745. doi:10.1007/s00063-007-1092-6

9. Culbert EL, Ashburn DA, Cullen-Dean G, Joseph JA, Williams WG, Blackstone EH, McCrindle BW, Congenital Heart Surgeons S (2003) Quality of life of children after repair of transposition of the great arteries. Circulation 108(7):857-862. doi:10.1161/01. CIR.0000084547.93252.9A

10. Daliento L, Mapelli D, Volpe B (2006) Measurement of cognitive outcome and quality of life in congenital heart disease. Heart 92(4):569-574. doi:10.1136/hrt.2004.057273

11. Diller GP, Inuzuka R, Kempny A, Alonso-Gonzalez R, Liodakis E, Borgia F, Lockhart CJ, Prapa M, Lammers AE, Swan L, Dimopoulos K, Gatzoulis MA (2013) Detrimental impact of socioeconomic status on exercise capacity in adults with congenital heart disease. Int J Cardiol 165(1):80-86. doi:10.1016/j.ijcard. 2011.07.097
12. Eslami B, Macassa G, Sundin O, Khankeh HR, Soares JJ (2014) Style of coping and its determinants in adults with congenital heart disease in a developing country. Congenit Heart Dis 9(4):349-360

13. Giardini A, Hager A, Pace Napoleone C, Picchio FM (2008) Natural history of exercise capacity after the Fontan operation: a longitudinal study. Ann Thorac Surg 85(3):818-821. doi:10. 1016/j.athoracsur.2007.11.009

14. Goldbeck L, Melches J (2005) Quality of life in families of children with congenital heart disease. Qual Life Res 14(8):1915-1924. doi:10.1007/s11136-005-4327-0

15. Hager A, Hess J (2005) Comparison of health related quality of life with cardiopulmonary exercise testing in adolescents and adults with congenital heart disease. Heart 91(4):517-520. doi:10.1136/hrt.2003.032722

16. Houyel L, Khoshnood B, Anderson RH, Lelong N, Thieulin AC, Goffinet F, Bonnet D, Group ES (2011) Population-based evaluation of a suggested anatomic and clinical classification of congenital heart defects based on the International Paediatric and Congenital Cardiac Code. Orphanet J Rare Dis 6:64. doi:10.1186/ 1750-1172-6-64

17. Janiec I, Werner B, Sieminska J, Ravens-Sieberer U (2011) Quality of life of children with mitral valve prolapse. Quality of life research: an international journal of quality of life aspects of treatment, care and rehabilitation 20(4):537-541. doi:10.1007/ s11136-010-9780-8

18. Kamphuis M, Ottenkamp J, Vliegen HW, Vogels T, Zwinderman KH, Kamphuis RP, Verloove-Vanhorick SP (2002) Health related quality of life and health status in adult survivors with previously operated complex congenital heart disease. Heart 87(4):356-362

19. Khairy P, Ionescu-Ittu R, Mackie AS, Abrahamowicz M, Pilote L, Marelli AJ (2010) Changing mortality in congenital heart disease. J Am Coll Cardiol 56(14):1149-1157. doi:10.1016/j.jacc. 2010.03.085

20. Krol YGM, Destrée-Vonka A, Lubbersb LJ, Koopmanc HM, Lasta BF (2003) Health related quality of life in children with congenital heart disease. Psychol Health 18:251-260

21. Landolt MA, Valsangiacomo Buechel ER, Latal B (2008) Healthrelated quality of life in children and adolescents after open-heart surgery. J Pediatr 152(3):349-355. doi:10.1016/j.jpeds.2007.07. 010

22. Latal B, Helfricht S, Fischer JE, Bauersfeld U, Landolt MA (2009) Psychological adjustment and quality of life in children and adolescents following open-heart surgery for congenital heart disease: a systematic review. BMC Pediatr 9:6. doi:10.1186/ 1471-2431-9-6

23. Mancini DM, Eisen H, Kussmaul W, Mull R, Edmunds LH Jr, Wilson JR (1991) Value of peak exercise oxygen consumption for optimal timing of cardiac transplantation in ambulatory patients with heart failure. Circulation 83(3):778-786

24. Marelli AJ, Mackie AS, Ionescu-Ittu R, Rahme E, Pilote L (2007) Congenital heart disease in the general population: changing prevalence and age distribution. Circulation 115(2):163-172. doi:10.1161/CIRCULATIONAHA.106.627224

25. Marino BS, Tomlinson RS, Drotar D, Claybon ES, Aguirre A, Ittenbach R, Welkom JS, Helfaer MA, Wernovsky G, Shea JA (2009) Quality-of-life concerns differ among patients, parents, and medical providers in children and adolescents with congenital and acquired heart disease. Pediatrics 123(4):e708-e715. doi:10.1542/peds.2008-2572

26. Maron BJ, Chaitman BR, Ackerman MJ, Bayes de Luna A, Corrado D, Crosson JE, Deal BJ, Driscoll DJ, Estes NA 3rd, Araujo CG, Liang DH, Mitten MJ, Myerburg RJ, Pelliccia A, Thompson PD, Towbin JA, Van Camp SP, Working Groups of the American Heart Association Committee on Exercise CR, Prevention, Councils on Clinical C, Cardiovascular Disease in the 
Y (2004) Recommendations for physical activity and recreational sports participation for young patients with genetic cardiovascular diseases. Circulation 109(22):2807-2816. doi:10.1161/01. CIR.0000128363.85581.E1

27. McCrindle BW, Williams RV, Mitchell PD, Hsu DT, Paridon SM, Atz AM, Li JS, Newburger JW, Pediatric Heart Network I (2006) Relationship of patient and medical characteristics to health status in children and adolescents after the Fontan procedure. Circulation 113(8):1123-1129. doi:10.1161/CIRCULA TIONAHA.105.576660

28. Mitchell JH, Maron BJ, Epstein SE (1985) 16th Bethesda conference: cardiovascular abnormalities in the athlete: recommendations regarding eligibility for competition. J Am Coll Cardiol 6(6): 1186-1232

29. Moola F, Fusco C, Kirsh JA (2011) The perceptions of caregivers toward physical activity and health in youth with congenital heart disease. Qual Health Res 21(2):278-291. doi:10.1177/1049732310384119

30. Moons P (2010) Patient-reported outcomes in congenital cardiac disease: are they as good as you think they are? Cardiol Young 20(Suppl 3):143-148. doi:10.1017/S1047951110001216

31. Moons P, Norekval TM (2006) Is sense of coherence a pathway for improving the quality of life of patients who grow up with chronic diseases? A hypothesis. Eur J Cardiovasc Nurs 5(1):16-20. doi:10.1016/j.ejcnurse.2005.10.009

32. Moons P, Van Deyk K, De Geest S, Gewillig M, Budts W (2005) Is the severity of congenital heart disease associated with the quality of life and perceived health of adult patients? Heart 91(9):1193-1198. doi:10.1136/hrt.2004.042234

33. Moons P, Budts W, De Geest S (2006) Critique on the conceptualisation of quality of life: a review and evaluation of different conceptual approaches. Int J Nurs Stud 43(7):891-901. doi:10. 1016/j.ijnurstu.2006.03.015

34. Muller J, Hess J, Hager A (2013) Sense of coherence, rather than exercise capacity, is the stronger predictor to obtain health-related quality of life in adults with congenital heart disease. Eur J Prev Cardiol 21(8):949-955. doi:10.1177/2047487313481753

35. Mussatto K, Tweddell J (2005) Quality of life following surgery for congenital cardiac malformations in neonates and infants. Cardiol Young 15(Suppl 1):174-178

36. Neuner B, Busch MA, Singer S, Moons P, Wellmann J, Bauer U, Nowak-Gottl U, Hense HW (2011) Sense of coherence as a predictor of quality of life in adolescents with congenital heart defects: a register-based 1-year follow-up study. JDBP 32(4):316-327. doi:10.1097/DBP.0b013e31821102ee

37. Overgaard D, Schrader AM, Lisby KH, King C, Christensen RF, Jensen HF, Idorn L, Sondergaard L, Moons P (2011) Patientreported outcomes in adult survivors with single-ventricle physiology. Cardiology 120(1):36-42. doi:10.1159/000333112

38. Ponikowski P, Francis DP, Piepoli MF, Davies LC, Chua TP, Davos CH, Florea V, Banasiak W, Poole-Wilson PA, Coats AJ, Anker SD (2001) Enhanced ventilatory response to exercise in patients with chronic heart failure and preserved exercise tolerance: marker of abnormal cardiorespiratory reflex control and predictor of poor prognosis. Circulation 103(7):967-972

39. Rassart J, Luyckx K, Apers S, Goossens E, Moons P, Di I (2012) Identity dynamics and peer relationship quality in adolescents with a chronic disease: the sample case of congenital heart disease. JDBP 33(8):625-632. doi:10.1097/DBP

40. Ravens-Sieberer U, Gosch A, Rajmil L, Erhart M, Bruil J, Duer W, Auquier P, Power M, Abel T, Czemy L, Mazur J, Czimbalmos A, Tountas Y, Hagquist C, Kilroe J, Kidscreen Group E (2005) KIDSCREEN-52 quality-of-life measure for children and adolescents. Expert Rev pharmacoecon Outcomes Res 5(3):353-364. doi:10.1586/14737167.5.3.353-\&gt

41. Ravens-Sieberer U, Auquier P, Erhart M, Gosch A, Rajmil L, Bruil J, Power M, Duer W, Cloetta B, Czemy L, Mazur J,
Czimbalmos A, Tountas Y, Hagquist C, Kilroe J, European KG (2007) The KIDSCREEN-27 quality of life measure for children and adolescents: psychometric results from a cross-cultural survey in 13 European countries. Qual Life Res 16(8):1347-1356. doi:10.1007/s11136-007-9240-2

42. Ravens-Sieberer U, Gosch A, Rajmil L, Erhart M, Bruil J, Power M, Duer W, Auquier P, Cloetta B, Czemy L, Mazur J, Czimbalmos A, Tountas Y, Hagquist C, Kilroe J, Group K (2008) The KIDSCREEN-52 quality of life measure for children and adolescents: psychometric results from a cross-cultural survey in 13 European countries. Value Health 11(4):645-658. doi:10.1111/j. 1524-4733.2007.00291.x

43. Ravens-Sieberer U, Herdman M, Devine J, Otto C, Bullinger M, Rose M, Klasen F (2014) The European KIDSCREEN approach to measure quality of life and well-being in children: development, current application, and future advances. Qual Life Res 23(3):791-803. doi:10.1007/s11136-013-0428-3

44. Robitail S, Ravens-Sieberer U, Simeoni MC, Rajmil L, Bruil J, Power M, Duer W, Cloetta B, Czemy L, Mazur J, Czimbalmos A, Tountas Y, Hagquist C, Kilroe J, Auquier P, Group K (2007) Testing the structural and cross-cultural validity of the KIDSCREEN-27 quality of life questionnaire. Qual Life Res 16(8):1335-1345. doi:10.1007/s11136-007-9241-1

45. Sable C, Foster E, Uzark K, Bjornsen K, Canobbio MM, Connolly HM, Graham TP, Gurvitz MZ, Kovacs A, Meadows AK, Reid GJ, Reiss JG, Rosenbaum KN, Sagerman PJ, Saidi A, Schonberg R, Shah S, Tong E, Williams RG, American Heart Association Congenital Heart Defects Committee of the Council on Cardiovascular Disease in the Young CoCNCoCC, Council on Peripheral Vascular D (2011) Best practices in managing transition to adulthood for adolescents with congenital heart disease: the transition process and medical and psychosocial issues: a scientific statement from the American Heart Association. Circulation 123(13):1454-1485. doi:10.1161/CIR.0b013e3182107c56

46. Solans M, Pane S, Estrada MD, Serra-Sutton V, Berra S, Herdman M, Alonso J, Rajmil L (2008) Health-related quality of life measurement in children and adolescents: a systematic review of generic and disease-specific instruments. Value Health 11(4):742-764. doi:10.1111/j.1524-4733.2007.00293.x

47. Sparacino PS, Tong EM, Messias DK, Foote D, Chesla CA, Gilliss CL (1997) The dilemmas of parents of adolescents and young adults with congenital heart disease. Heart Lung 26(3):187-195

48. Spijkerboer AW, Utens EM, De Koning WB, Bogers AJ, Helbing WA, Verhulst FC (2006) Health-related quality of life in children and adolescents after invasive treatment for congenital heart disease. Qual Life Res 15(4):663-673. doi:10.1007/s11136-0053692-z

49. Spijkerboer AW, Utens EM, Bogers AJ, Verhulst FC, Helbing WA (2008) Long-term behavioural and emotional problems in four cardiac diagnostic groups of children and adolescents after invasive treatment for congenital heart disease. Int $\mathrm{J}$ Cardiol 125(1):66-73. doi:10.1016/j.ijcard.2007.02.025

50. Tahirovic E, Begic H, Nurkic M, Tahirovic H, Varni JW (2010) Does the severity of congenital heart defects affect diseasespecific health-related quality of life in children in Bosnia and Herzegovina? Eur J Pediatr 169(3):349-353. doi:10.1007/ s00431-009-1060-7

51. Tahirovic E, Begic H, Tahirovic H, Varni JW (2011) Quality of life in children after cardiac surgery for congenital heart disease. Coll Antropol 35(4):1285-1290

52. Teixeira FM, Coelho RM, Proenca C, Silva AM, Vieira D, Vaz C, Moura C, Viana V, Areias JC, Areias ME (2011) Quality of life experienced by adolescents and young adults with congenital heart disease. Pediatr Cardiol 32(8):1132-1138. doi:10.1007/ s00246-011-0039-0 
53. Utens EM, Bieman HJ, Verhulst FC, Meijboom FJ, Erdman RA, Hess J (1998) Psychopathology in young adults with congenital heart disease. Follow-up results. Eur Heart J 19(4):647-651

54. Uzark K, Jones K, Slusher J, Limbers CA, Burwinkle TM, Varni JW (2008) Quality of life in children with heart disease as perceived by children and parents. Pediatrics 121(5):e1060 e1067. doi:10.1542/peds.2006-3778

55. Wray J, Maynard L (2006) The needs of families of children with heart disease. JDBP 27(1):11-17 